\title{
Putting Autopoietic Bodies Under Pressure
}

Adaptive Behavior

I-2

(C) The Author(s) 2019

Article reuse guidelines:

sagepub.com/journals-permissions DOI: I0.1 I77//0597|23/9840277 journals.sagepub.com/home/adb (SAGE

\section{Mog Stapleton}

\begin{abstract}
This commentary puts pressure on the "resistance to dissipation" criterion for Villalobos and Razeto-Barry's conception of "autopoietic bodies." It argues that resistance to dissipation can only be assessed against the backdrop of certain background conditions. If this is right then it is no longer so clear that systems not considered as autopoietic bodies but merely as autopoietic systems do not fulfill the requirements of being an autopoietic body.
\end{abstract}

\author{
Keywords \\ Autopoiesis, autonomy, organism, living systems \\ Handling Editor: Tom Froese, National Autonomous University of Mexico, Mexico
}

Villalobos and Razeto-Barry (henceforth V\&RB) argue that amending the definition of living beings in Autopoietic Theory from "autopoietic systems" to "autopoietic bodies" better captures the original spirit of the proposal. Furthermore, by characterizing living beings as autopoietic bodies, they are able to make a principled distinction between systems that we commonly identify as organisms and the larger (potentially autopoietic) systems of which these organisms may also be a part. On this view, (a) being an autopoietic system is not sufficient for being a living system, only necessary, and (b) autopoietic systems are not defined as producing their own physical boundary. Rather, what is necessary for being a living system (or "organism") is that an autopoietic system's material components are in physical proximity and are resistant to dissipationwhat V\&RB refer to as being an "autopoietic body."

This distinction between autopoietic systems and autopoietic bodies opens up the space for "autopoiesis" to be used in the more general, abstract way that it already often is in work inspired by Maturana (such as in social systems theory). Used in this way "autopoiesis"- the abstraction of the autopoietic organization from its biological instantiation in for example, a cellpotentially maps on to what the enactivists refer to as "autonomous organisation." Similarly, what V\&RB are calling "autopoietic bodies" seems to map onto what enactivists call "autopoiesis" while allowing us to coherently include multicellular organisms within that category. I see this rebranding as having the potential to move us beyond terminological differences giving autopoietic theorists and enactivists a new shared language that will do a better job of bringing out what they have in common. However, I have worries about defining "autopoietic bodies" in terms of physical proximity and resistance to dissipation.

V\&RB replace the role that the boundary has traditionally played in cellular/organismic autopoietic systems with physical proximity and resistance to dissipation. Physical proximity on its own is clearly not enough to play the role of distinguishing an autopoietic body. On the face of it the requirement that a physically proximal autopoietic system is also resistant to dissipation does seem to allow this. However, the resistance to dissipation criterion is worryingly dependent on environmental conditions rather than internal dynamics. While it might be the case that at sea level on planet earth it is my internal organization that makes my body resistant to dissipation this is contingent on the pressure in which my body has evolved. Change the pressure

Eidyn Research Centre, School of Philosophy, Psychology and Language Sciences, The University of Edinburgh, Edinburgh, UK

\section{Corresponding author:}

Mog Stapleton, Eidyn Research Centre, School of Philosophy, Psychology and Language Sciences, The University of Edinburgh, Dugald Stewart Building, 3 Charles Street, EH8 9AD Edinburgh, UK.

Email: mog.stapleton.philosophy@gmail.com 
enough in either direction and my body's resistance to dissipation reduces until it finally doesn't pose any resistance. This is, of course, an example outwith the realms of those in which the organism that is my body has evolved to be a system. Nevertheless, the example highlights two things: (a) that resistance to dissipation comes in degrees, and V\&RB have not yet made clear what the lower bound of this might have to be to satisfy the requirements for being an autopoietic body, and (b) that once we acknowledge that resistance to dissipation can only be assessed against the backdrop of certain background conditions then it is no longer so clear that systems not considered as autopoietic bodies but merely as autopoietic systems, such as V\&RB's example of Gaia, do not fulfill the requirements of being an autopoietic body. Why is the earth's gravity a different kind of background condition from the pressure level that keeps me from dissipating?

\section{Acknowledgements}

Many thanks to Dave Ward for his valuable comments on a previous draft of this commentary.

\section{Declaration of Conflicting Interests}

The author(s) declared no potential conflicts of interest with respect to the research, authorship, and/or publication of this article.

\section{Funding}

The author(s) received no financial support for the research, authorship, and/or publication of this article.

\section{ORCID iD}

Mog Stapleton iDhttps://orcid.org/0000-0002-1244-4317

\section{About the Author}

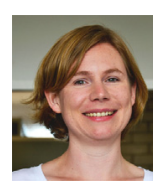

Mog Stapleton is a postdoc in philosophy at the University of Edinburgh. Her background is in philosophy of cognitive science with a specific focus on embodied, enactive and affective approaches to cognition and consciousness. 